\title{
VASCULAR ACCESS BLEEDING SURGERY IN A PEDIATRIC UNIVERSITY HOSPITAL
}

Latorre J., Pérez Ferrer A., Dennis Filippini S., De Vicente Sánchez J.

Background:

La Paz University Hospital, Dept of Anaesthesiology \& Intensive Care, Madrid, Spain

- The cannulation and vascular access in the child is essential.

- It presents greater difficulty in the infant and young children, requiring multiple attempts.

- At risk of massive hemorrhage, larger gauges are required which further complicates the process.

\section{Method:}

- A description of the clinical practice of the peripheral and central vascular accesses that is more adequate for surgeries with risk of massive hemorrhage.

- Analyzing the most suitable gauges, types of catheters and technique, as it is done in our institution.

- Including limit situations, such as liver transplantation, where veins that drain into the inferior vena cava should not be used.

\section{Discussion:}

- Literature concerning catheterization of vascular access in children refers to situations in which only maintenance fluid is required.

- Both access and caliber should be adapted to:

$\checkmark$ patient's age

$\checkmark$ type of surgery

$\checkmark$ clinical situation

\begin{tabular}{|l|l|l|l|}
\hline \multicolumn{3}{c}{ LITERATURE } & \multicolumn{2}{c|}{ LA PAZ UNIVERSITY HOSPITAL } \\
\hline AGE & $\begin{array}{l}\text { CENTRALL LINE } \\
\text { Caliber }\end{array}$ & $\begin{array}{l}\text { MASSIVE HEMORRHAGE: } \\
\text { CENTRAL LINE Caliber }\end{array}$ & $\begin{array}{l}\text { MASSIVE HEMORRHAGE: } \\
\text { Introducer Sheath } \\
\text { Caliber/Length }\end{array}$ \\
\hline PRETERM & $3 \mathrm{Fr}$ & $4 \mathrm{Fr}$ & $3 \mathrm{Fr} / 4 \mathrm{~cm}$ \\
\hline $\begin{array}{l}\text { NEONATO AND INFANT } \\
\text { SCHOOL }\end{array}$ & $4-4,5 \mathrm{Fr}$ & $4,5-5 \mathrm{Fr}$ & $4-5 \mathrm{Fr} / 5,5 \mathrm{~cm}$ \\
\hline PRESCHOOL & $4,5-5,5 \mathrm{Fr}$ & $5,5-7-8 \mathrm{Fr}$ & $6 \mathrm{Fr} / 5,5-8,5 \mathrm{~cm}$ \\
\hline SCHOOL & $5,5-6 \mathrm{Fr}$ & $7-8 \mathrm{Fr}$ & $7 \mathrm{Fr} / 7-12 \mathrm{~cm}$ \\
\hline TEEN & $7 \mathrm{Fr}$ & $\geq 8 \mathrm{Fr}$ & $\geq 8 \mathrm{Fr} / 11-12 \mathrm{~cm}$ \\
\hline
\end{tabular}
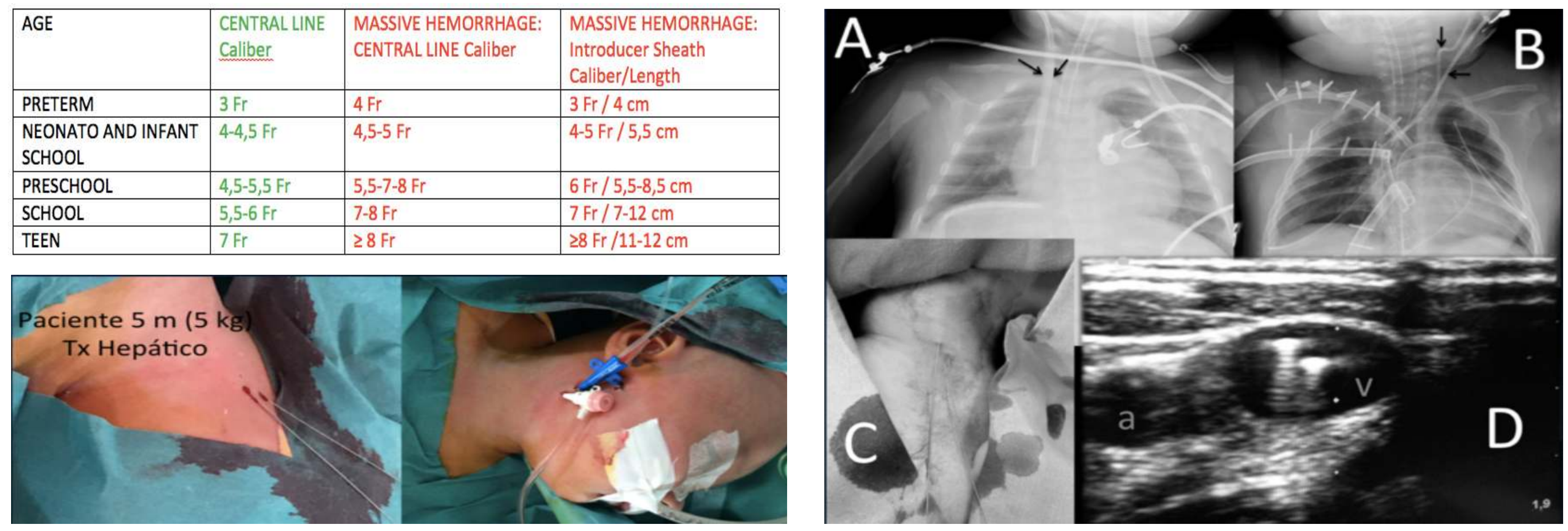

- In infants with difficult canalization: the saphenous vein and the external jugular vein are useful as peripheral access.

- For the central compartment, ultrasound-guided technique is of choice.

- For situations with significant bleeding, the right internal jugular vein is the most frequently used in our center.

- In situations of extreme urgency in important to not forget the intraosseous access.

\section{Conclusions:}

* The vascular canalization in pediatrics requires a greater learning curve than in the adult, requiring knowledge of the technique and the appropriate material.

* The case of potential or actual situations of massive hemorrhage requires considering specific implications. 